\title{
MICROWAVE PRETREATMENT OF LIGNOCELLULOSIC BIOMASS TO RELEASE MAXIMUM PHENOLIC ACIDS
}

\section{A. BICHOT ${ }^{1}$, M. RADOIU ${ }^{2}$, Nicolas BERNET ${ }^{1}$, Valérie MECHIN $^{3}$, J-P. DELGENÈS ${ }^{1}$, D. GARCÍA-BERNET ${ }^{1 *}$}

\author{
${ }^{1}$ LBE, Univ Montpellier, INRA, 102 Avenue des Etangs, 11100 Narbonne, France \\ ${ }^{2}$ Microwave Technologies Consulting, 153 rue des colverts, 69140 Rillieux la Pape, France \\ ${ }^{3}$ INRA Institut Jean-Pierre Bourgin, 78026 Versailles, France \\ * Corresponding author: E-mail: diana.garcia-bernet@inra.fr; tel: +33 (0)4 684664 28; \\ ORCID: 0000-0003-3163-8819
}

Keywords: pressure microwaves, biomass pretreatment, phenolic acids

\begin{abstract}
Biomass pretreatment is a critical issue for successful biorefinery deployment and thus new competitive and sustainable technologies are needed for efficient biomass bioconversion. Microwave (MW) treatment has emerged as an interesting option; nevertheless, the action mode of MW on lignocellulosic biomass is not fully understood and studies dealing with MW pretreatment do not address this important question.

The aim of this article is to provide an analysis of microwave effects on phenolic acids release from corn stalks, a biomass of industrial interest. MW treatments were performed using water as a solvent and a power density of $2.38 \mathrm{~W} / \mathrm{g}$. Incident, reflected \& absorbed power levels and reaction temperature were monitored on-line. MW treatments were compared to a conventional heating treatment, a control treatment without heating and a high $\mathrm{NaOH}$ consumption reference extraction method for phenolic acids.

Optimal MW conditions were chosen to increase phenolic acids release: pressurized test (300W and 180s) allowed the extraction of 10 times more ferulic acid than classic microwave treatment.

Finally, these different heating possibilities were compared from an economic and environmental point of view.
\end{abstract}

\section{Introduction}

The objectives fixed by world's governments concerning energy transition have aroused interest on lignocellulosic biomass utilization for bioenergy and green chemistry applications. However, due to their resistant structure, deconstructive pretreatments are necessary to render possible biological conversions of these lignocellulosic residues [1]. Microwave (MW) treatment has been reported as efficient in many biotechnology fields; biomass pretreatment for biorefinery purposes is another possible application [2]. This work presents the effects of MW pretreatment on underexploited natural agri-food biomass of economic interest: corn stalks.

Various heating types were studied including conventional heating and microwave heating at atmospheric pressure or with an increase in pressure. Effects were evaluated by a complete biomass characterization before and after treatment, with main focus on phenolic acids (PA) release and more specifically ferulic acid (FA) and para-coumaric acid ( $p \mathrm{CA})$. In the tested conditions and when compared to the high $\mathrm{NaOH}$ consumption reference extraction method for phenolic acids, the atmospheric pressure (open vessel) microwave treatment did not allow attaining high acid extraction yields. In order to increase yields, microwave treatments under pressure were carried out to reach higher temperatures while taking care as to not exceed $150^{\circ} \mathrm{C}$ - the acid denaturation temperature [3] and to avoid the formation of 
inhibitors. Energy balances were also calculated to demonstrate the advantages of MW in terms of energy consumption and processing time.

\section{Materials and methods}

\section{Raw biomass and composition analysis}

INRA IJPB (Versailles-Grignon unit, Versailles Cedex, 78026, France) supplied corn stalks (F 98902) harvested in September 2016.

Air dried samples were coarsely crushed (Viking, model GE 220, STIHL, Stuttgart, Germany) before being finely ground to $1 \mathrm{~mm}$ (using a Fritsch Pulverisette 19) and sieved to retain only particles between 200 and $1000 \mu \mathrm{m}$. Ground and sieved samples were kept in closed boxes at ambient temperature before usage. Biomass composition was determined using Van Soest protocol [4], which allows determining the amount of parietal polymers before and after treatment. Van Soest protocol is based on mass sequential partitioning of cell walls, from most extractible to less extractible, with successive extractions using different solvents (water, neutral detergent solution, acid detergent solution, and sulfuric acid $72 \%$ ). Phenolic compounds were analysed by HPLC using a HPLC-DAD Waters system: autosampler 717, multisolvent delivery system 600, Diode Array Detector 2996. All chemicals were purchased from Sigma-Aldrich Chemical. High purity water (Merck Millipore Quantum TEX) was used for all pretreatments and analysis.

\section{Biomass pretreatment}

Based on previous works [5], optimal conditions for extracting phenolic acids were determined. Alkaline water ( $\mathrm{pH}=8.5$ obtained by adding $6.7 \mathrm{mmol} \mathrm{NaOH}$ to $200 \mathrm{ml}$ water), $\mathrm{S} / \mathrm{L}$ ratio 1:21 (w:w), total volume of $200 \mathrm{ml}$, incident power of $500 \mathrm{~W}$, treatment duration of 270 s and high stirring were determined as adequate conditions to extract phenolic acids. Nevertheless, in this study water was chosen as the solvent to highlight the performance of microwave processing under mild chemical conditions. Samples underwent $1 \mathrm{~h}$ pre-soaking at ambient temperature before pretreatment.

All MW pretreatments were performed with a Minilabotron 2000 (SAIREM, FRANCE), operating at $2.45 \mathrm{GHz}$ with a maximum power of $2 \mathrm{~kW}$. The equipment was used for two different MW pretreatments: classic microwave pretreatment (CMW) and pressurized microwave pretreatment (PMW). Each pretreatment was performed in duplicate at constant incident power to ensure a power density of $2.38 \mathrm{~W} / \mathrm{g}(500 \mathrm{~W}$ and $270 \mathrm{~s}$ for CMW and $300 \mathrm{~W}$ and 180s for PMW). Temperature (excepted for PMW), incident power and reflected power were recorded during the treatment. The different elements of the devices are illustrated on Figure 1.
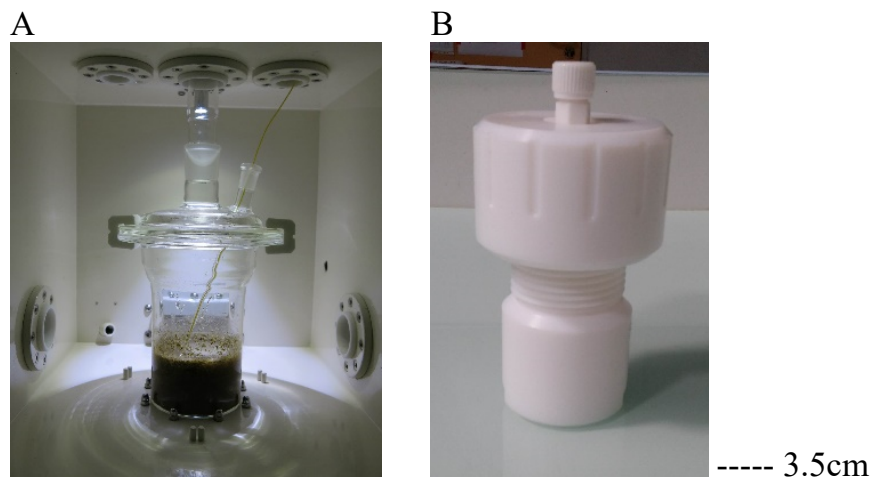

Fig. 1. Installation ready for operation: CMW (A) and PMW (B) 
A conventional heating (Conv) without using electromagnetic waves was also carried out as to compare the energy performance of the two types of heating. The reactor containing the same reaction mixture as the microwave treated sample was immersed in a heat-stabilised oil bath at $110^{\circ} \mathrm{C}$ for $360 \mathrm{~s}$. The oil bath was positioned on a laboratory heating plate.

Two control treatments (soaked biomass sample without any heating) were also carried out. The first one, using water for $1 \mathrm{~h}$ soaking, was considered as a negative control $\left(\mathrm{C}^{-}\right)$. The second one, using $\mathrm{NaOH} 10 \%(\mathrm{w} / \mathrm{w})$ for $24 \mathrm{~h}$ was considered as a positive control $\left(\mathrm{C}^{+}\right)$ allowing the extraction of a large quantity of phenolic acids [6].

After each treatment, the reactor was cooled to room temperature for $15 \mathrm{~min}$ before weighing and filtering through a $200 \mu \mathrm{m}$ sieve. Solid was washed with $300 \mathrm{~mL}$ of deionized water to remove reagents (in the case of $\mathrm{NaOH}$ treatment) and by-products inhibiting further biological reactions. Solid was placed 7 days at $40^{\circ} \mathrm{C}$ to dry. The dry matter content was measured to determine the amount of solubilized matter during processing (treatment soluble). Supernatant was filtered through cellulose filter $(2.7 \mu \mathrm{m})$ and preserved at $-20^{\circ} \mathrm{C}$ until further analysis. The overall process of a microwave test is shown in Fig. 2.
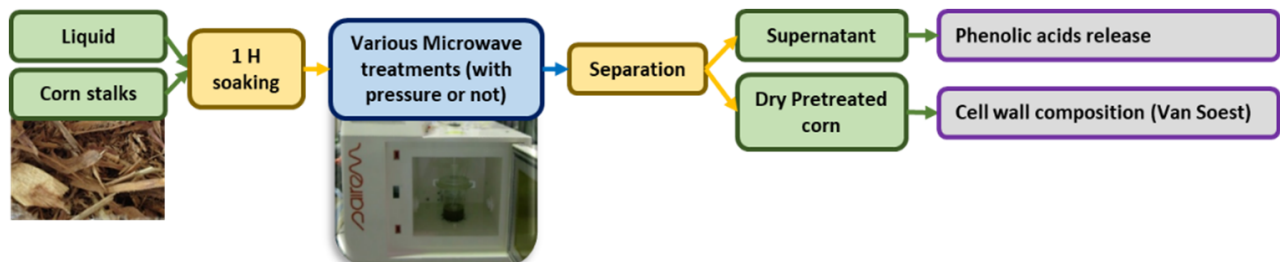

Fig. 2. Global microwave pretreatment scheme

Microwave effects on biomass composition and on phenolic acids release were analysed with ANOVA and considered significant when p-value $<0.05$ with residuals distributed according to a normal law.

\section{Energy calculations}

In order to compare Conv, CMW and PMW from an energy point of view, energy consumption for each test was measured using an amperometric clamp allowing to record intensity data. Knowing that the voltage in France is $230 \mathrm{~V}$, the power was determined by equation [1], with $\cos (\varphi)$ corresponding to the phase shift between the alternating voltage and current.

$P_{\text {real }}=$ U.I $\cos (\varphi)$

equation [1]

Considering that the microwave and the plate are purely resistive, the current and the voltage are in phase $(\varphi=0)$ and $\cos (\varphi)=1$. The power can be expressed with equation [2]:

$\mathrm{P}_{\text {real }}=\mathrm{U} . \mathrm{I}$

equation [2]

Microwave yield can then be calculated from the incident energy divided by the consumed energy following equation [3]. The yield corresponds to the mains electrical efficiency and to the magnetron efficiency. The yield was calculated for three different power levels, $1000 \mathrm{~W}, 500 \mathrm{~W}$ and $300 \mathrm{~W}$ for $800 \mathrm{~s}$, and compared to that of the pilot's manual $(65 \%)$

$\eta_{M W}=P_{i} / P_{\text {real }}$

equation [3] 
Concerning conventional heating, the maximum heating power of the plate is $1000 \mathrm{~W}$. The time required to heat the plate to $100^{\circ} \mathrm{C}$ before starting the test must be also considered equation [4]. The yield was not calculated as the plate is not optimized and a significant portion of this energy is lost due to heat losses from the oil bath.

$\mathrm{E}_{\mathrm{CONV}}=\left(\mathrm{P}_{\text {plate }} \cdot \mathrm{t}_{\text {heating }}+\mathrm{P}_{\text {plate }} \cdot \mathrm{t}_{\text {test }}\right) / \eta_{\text {plate }}$

equation [4]

\section{Results and discussion}

\section{Parietal composition}

Using Van Soest method, the parietal composition of raw biomass and each pretreated sam ple was measured, Fig. 3. The raw biomass composition corresponds to values found in lite rature [7, 8]. Fig. 3 shows that total soluble content (from treatment and from Van Soest fir st step) doesn't significantly differ according to the different treatments tested except for th e case of $\mathrm{C}+$ and PMW treatments ( $p=6.4 \mathrm{e}-09$ and $p=0.000663$ respectively). High conce ntrated $\mathrm{NaOH}$ and pressurized MW treatments have an impact on cell wall content solubili zation and more specifically on hemicellulose solubilization. Indeed, hemicellulose signific antly varies when $\mathrm{C}^{+}(p=0.00326)$ is used and is significantly different at $0.1 \%$ risk using PMW $(p=0.06359)$. Pressure and $\mathrm{NaOH}$ are well known factors affecting biomass compos ition $[9,10]$. The phenolic acids being very strongly embedded in the parietal network, if th e latter is partially destructured, then a significant release of phenolic acids can be expected

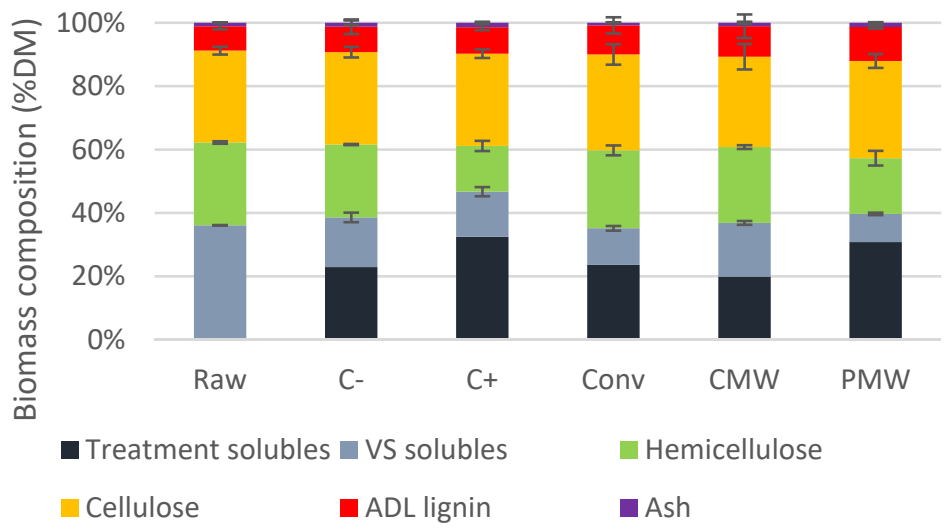

Fig. 3. Raw and pretreated biomass composition with Van Soest method

Phenolic acids were quantified in the raw biomass and the obtained values were the following: $4.2 \mathrm{mg} \mathrm{FA} / \mathrm{g} \mathrm{DM}$ and $13.1 \mathrm{mg} p \mathrm{CA} / \mathrm{gDM}$. Extraction yields in the liquid and $p$ values were calculated using equation [5] and results are summed up in Table 1.

$\mathrm{PA}_{\text {yield }}=\left(\mathrm{PA}_{\text {liberated in soluble content }} m g / g\right) /\left(\mathrm{PA}_{\text {initial }} m g / g\right)$

equation [5]

From Table 1 we can see that phenolic acids extraction significantly increased when PMW treatment was employed ( $p=0.00755)$; FA extraction yield is more than ten times higher than in $\mathrm{C}^{-}$test, which is consistent with the previous parietal composition analysis. In the case of $\mathrm{C}^{+}$treatment, FA extraction yield reached $94 \%$, which confirms the theory of almost complete extraction of FA by $\mathrm{NaOH}$. This is also visible in the case of $p \mathrm{CA}$ extraction yield: $\mathrm{C}^{+}$extraction yield reaches $45 \%$. Moreover, $p C A$ extraction yield is significantly increased 
using PMW ( $p=0.00323)$. Temperatures higher than $100^{\circ} \mathrm{C}$ are necessary to disrupt cell wall and gain access to phenolic acids [3].

Tab. 1. Phenolic acid extraction after various treatments

\begin{tabular}{l|cccc}
\hline & FA yield & FA p value & $p$ CA yield & $p$ CA $p$ value \\
\hline $\mathrm{C}^{-}$ & $0.6 \%$ & $/$ & $1.4 \%$ & $/$ \\
$\mathrm{C}^{+}$ & $94.0 \%$ & $2.45 \mathrm{e}-09$ & $45.7 \%$ & $5.47 \mathrm{e}-10$ \\
& & $* * *$ & & $* * *$ \\
Conv & $1.0 \%$ & 0.91738 & $1.2 \%$ & 0.89203 \\
CMW & $1.5 \%$ & 0.76602 & $1.1 \%$ & 0.82984 \\
PMW & $11.3 \%$ & $0.00755 * *$ & $6.2 \%$ & $0.00323 * *$ \\
\hline
\end{tabular}

\section{Energy consumption comparison}

Using equation [3], MW yield was calculated for incident power of $1000 \mathrm{~W}, 500 \mathrm{~W}$ and $300 \mathrm{~W}$ for $800 \mathrm{~s}$. No variation in intensity was detected over time and yields are represented in Fig. 4. According to Fig. 4, the MW yield follows an affine function depending on the incident MW power: the higher the incident power, the better the efficiency. The yield achieved at $1000 \mathrm{~W}$ is close to that expected for this device.

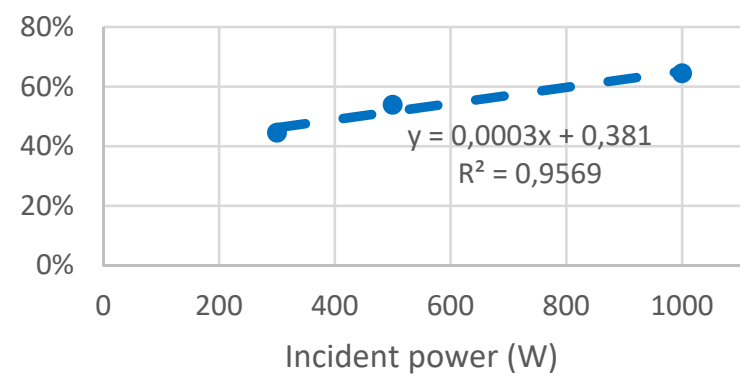

Fig. 4. MW yields vs. MW incident power

Using equations [2], [3] and [4], the total energy consumption was estimated for each treatment, Table 2 . The energy required to produce $\mathrm{NaOH}$ was not considered and as such explaining why $\mathrm{C}+$ and $\mathrm{C}$ - did not consume any energy and why were not represented.

Results listed in Table 2 show that the energy required for only one batch pretreatment is twice higher in conventional treatment $(383 \mathrm{~kJ}$ to treat $10 \mathrm{~g})$ than in pressurized treatment $(121 \mathrm{~kJ}$ to treat $2 \mathrm{~g})$. Nevertheless, it is essential to account for the quantity of treated material. In the case of PMW, the available reactor did not allow the treatment of more than $2 \mathrm{~g} / \mathrm{batch}$ while the CMW set-up allowed for $10 \mathrm{~g} / \mathrm{batch}$ treatment. Therefore, at present an extrapolation of the results at industrial scale will be not attempted. However, it is interesting to compare the two treatment methods and therefore the PMW treatment loses interest because of the high price to treat $10 \mathrm{~g}(606 / 10 \mathrm{~g})$. The design of a MW pressured reactor with a larger volume would be essential in order to scale up the process and reduce the cost. With reference to the available equipment, CMW treatment was more advantageous $(250 \mathrm{~kJ} / 10 \mathrm{~g})$ and allowed $100^{\circ} \mathrm{C}$ pretreatment temperatures to be reached quickly compared to conventional heating $(2225 \mathrm{~kJ} / 10 \mathrm{~g})$. This last treatment could be improved by installing oil bath insulation and optimized heating plate. 
Lastly, it would be interesting to know how much could be gained from the phenolic acids extracted via PMW. Due to their high added value, these molecules could compensate for the high cost of the microwave treatment process. Thus, the overall cost-effectiveness of the process would be determined.

Tab. 2. Energy consumption for each treatment: Conv = conventional heating, CMW = Classic microwave treatment at 500W, PMW = Pressurized microwave treatment at 300W

\begin{tabular}{c|ccc}
\hline & Conv & CMW $(500 W)$ & $P M W(300 W)$ \\
\hline Pretreated mass $(\mathbf{g})$ & $\mathbf{1 0}$ & $\mathbf{1 0}$ & $\mathbf{2}$ \\
$\mathrm{P}(\mathrm{W})$ & 1000 & 500 & 300 \\
$\eta$ & & $54 \%$ & $45 \%$ \\
\hline Heating duration $(\mathrm{s})$ & 1800 & & \\
Heating energy $(\mathrm{kJ})$ & 1842 & & 180 \\
\hline Batch test duration $(\mathrm{s})$ & 360 & 270 & 121 \\
Batch test energy $(\mathrm{kJ})$ & 383 & 250 & 606 \\
\hline Total energy $(\mathrm{kJ} / 10 \mathrm{~g})$ & 2225 & 250 & 0.17 \\
Total energy $(\mathrm{kWh} / 10 \mathrm{~g})$ & 0.62 & 0.07 & $\mathbf{0 . 0 2 5}$ \\
Treatment cost $(\mathbf{\epsilon} / \mathbf{1 0 g}) *$ & $\mathbf{0 . 0 9 3}$ & $\mathbf{0 . 0 1 0}$ & \\
\hline
\end{tabular}

*Considering $0.15 € / \mathrm{kWh}$ in France

\section{Conclusion}

This study demonstrates that microwaves can be used to pretreat lignocellulosic biomass. Using a PTFE reactor especially designed for this work, temperatures above $100^{\circ} \mathrm{C}$ were reached and resulted in the release of phenolic acids, molecules of high interest currently. In addition, from an economic viewpoint, the technology allows biomass to be processed quickly compared to conventional treatment. Energy consumption is significantly reduced. Nevertheless, technological advances are necessary for process scaling-up; i.e. the treatment of higher quantities of biomass in a pressurized environment and more adapted reactor. At this point, as a more in-depth economic analysis is needed, the authors would not discuss CAPEX, OPEX and ROI of such equipment.

\section{Acknowledgements}

Authors would like to thank Nicolas Holfeltz, NH Verre France for his help in designing the microwave reactor. The authors also thank Yannick Sire from INRA Pech Rouge for phenolic acids analysis.

\section{References}

1. Bichot, A., Delgenes, J.P., Mechin, V., Carrere, H., Bernet, N., Garcia-Bernet, D. 2018. Understanding biomass recalcitrance in grasses for their efficient utilization as biorefinery feedstock. Reviews in Environmental Science and Bio-Technology, 17(4), 707-748.

2. Bundhoo, Z.M.A. 2018. Microwave-assisted conversion of biomass and waste materials to biofuels. Renewable and Sustainable Energy Reviews, 82, 11491177.

3. Liazid, A., Palma, M., Brigui, J., Barroso, C.G. 2007. Investigation on phenolic compounds stability during microwave-assisted extraction. Journal of Chromatography A, 1140(1-2), 29-34.

4. Goering, H.K. and Van Soest P.J. 1970. Forage Fiber Anlysis (Apparatus, Reagents, Procedures, and some applications). USDA ARS Agricultural Handbook 379. US Government Printing Office, Washington, DC 
5. Bichot, A., Lerosty, M., Geirnaert, L., Méchin, V., Carrère, H., Bernet, N., Delgenès, J.P., García-Bernet, D. 2019. Soft microwave pretreatment to extract phydroxycinnamic acids from grass stalks. Submitted to Industrial crops and products

6. Mathew, S., Abraham, T.E. 2004. Ferulic acid: An antioxidant found naturally in plant cell walls and feruloyl esterases involved in its release and their applications. Critical Reviews in Biotechnology, 24(2-3), 59-83.

7. Provan, G.J., Scobbie, L., Chesson, A. 1994. Determination of phenolic-acids in plant-cell walls by microwave digestion. Journal of the Science of Food and Agriculture, 64(1), 63-65.

8. van der Weijde, T., Kamei, C.L.A., Torres, A.F., Vermerris, W., Dolstra, O., Visser, R.G.F., Trindade, L.M. 2013. The potential of C4 grasses for cellulosic biofuel production. Frontiers in Plant Science, 4, 18.

9. Thomas, H.L., Seira, J., Escudie, R., Carrere, H. 2018. Lime Pretreatment of Miscanthus: Impact on BMP and Batch Dry Co-Digestion with Cattle Manure. Molecules, 23(7), 13.

10. Gaspar, M., Kalman, G., Reczey, K. 2007. Corn fiber as a raw material for hemicellulose and ethanol production. Process Biochemistry, 42(7), 1135-1139. 